\title{
The Association Between Depressive Symptoms and Length of Hospital Stay Following Coronary Artery Bypass Graft is Moderated by Perceived Control
}

Mohannad Eid AbuRuz

Aaliyah Momani

AbedAlmajeed Shajrawi

Clinical Nursing Department, Faculty of Nursing, Applied Science Private

University, Amman, Jordan
This article was published in the following Dove Press journal:

Risk Management and Healthcare Policy

Purpose: Depressive symptoms can negatively influence patient outcomes after coronary artery bypass graft surgery (CABG). Preoperative depressive symptoms can be associated with a longer hospitalization. Perceived control moderates the effect of anxiety on length of stay (LOS) among CABG patients, but its effect on depressive symptoms and LOS is not well studied. This study tests whether perceived control moderates the relationship between depressive symptoms and LOS among patients following CABG.

Patients and Methods: This prospective cohort study was conducted on 220 participants recruited from three hospitals in Jordan. Participants' depressive symptom levels were measured using the depression subscale of the Hospital Anxiety and Depression Scale. Perceived control was measured by the Arabic version of the Control Attitude ScaleRevised. Length of stay was obtained from medical records. Data were analyzed using multiple regression and simple slope analysis.

Results: Females had higher levels of depressive symptoms (mean [SD]: 16.7 [5.2] vs 11.6 [5.6], $\mathrm{P}<0.05$ ), and longer LOS (mean [SD]: 17.5 [12.7] vs 10.3 [9.0], $\mathrm{P}<0.001$ ) compared to male patients. Being female increased the length of stay by 0.18 days. Every one-unit increase in preoperative depressive symptoms increased LOS by 0.37 days. Perceived control has a protective effect; every one unit increase in perceived control decreased LOS by 0.28 days. Moreover, perceived control moderates the relationship between depressive symptoms and LOS.

Conclusion: This study suggests that depressive symptoms and perceived control play an important role in the recovery among post-CABG patients. Application of policies to assess depressive symptoms and improve perceived control prior to $\mathrm{CABG}$ by health care providers might decrease morbidity and mortality.

Keywords: depressive symptoms, perceived control, coronary artery bypass graft, length of stay

\section{Introduction}

Cardiovascular diseases (CVDs) remain the main cause of death worldwide, ${ }^{1}$ and over two-thirds of these deaths occur in developing countries. ${ }^{2}$ One of the most common CVDs is Coronary Heart Disease (CHD), ${ }^{3}$ and its treatments and controlling factors affecting outcomes are of fundamental significance for health systems. Coronary Artery Bypass Graft Surgery (CABG) is the most appropriate
Correspondence: Mohannad Eid AbuRuz Clinical Nursing Department, Faculty of Nursing, Applied Science Private

University, PO Box 142, Shafa Badran,

Amman, I 1934, Jordan

Tel +962790262408

Fax +96265232899

Email mohannadeid@yahoo.com
Risk Management and Healthcare Policy 202I:|4 |499-I507 
management for CHD when less invasive medical options are not appropriate. $\mathrm{CABG}$ is a common surgery for those patients because of its beneficial outcomes. ${ }^{3-6}$ This is evident as nearly one million CABG surgeries were done worldwide since more than ten years ago. ${ }^{6}$

Successful CABG outcomes include improved patient well-being and efficient status, reduced signs and symptoms of disability, decreased anxiety and depressive symptoms (DS), and improved quality of life. ${ }^{4,5,7,8}$ Nevertheless, CABG itself is a worrying and disturbing incident for patients, known to be accompanied by undesirable psychosomatic results in both the preoperative and postoperative periods. ${ }^{9,10}$ Furthermore, some negative consequences following this surgery remain unresolved. $^{4,6,11,12}$ For example, more than a third of patients complain of chest pain, and roughly half of them have activity restriction one year later. ${ }^{11}$ Thus, recognizing changeable associated factors contributing to these adverse outcomes might improve patients' reaction after CABG.

Some studies showed that these factors included psychological factors; the effects of these psychological factors were as important as or even more important than physiological ones. ${ }^{13-16}$ DS are considered as an important factor affecting the recovery following acute cardiac events, such as myocardial infarction and angina. The prevalence rates of preoperative DS range from 14 to $60 \%,{ }^{7,8,17-20}$ and increase up to $98 \%$ postoperatively. ${ }^{6,20,21}$ However, more than half of patients undergoing $\mathrm{CABG}$ are not routinely assessed and/or managed for DS. ${ }^{6,20,22}$

DS, if not assessed and treated well, negatively affect outcomes after CABG. Preoperative DS were independent predictors for longer hospital length of stay (LOS), ${ }^{20}$ readmissions, and chest pain, as well as higher incidence of delirium, deaths, and postoperative DS. ${ }^{4-8,23}$ Furthermore, preoperative DS increased the incidence of postoperative inflammation, depressed patient resistance, and decreased wound healing, all of which increased postoperative LOS. $^{6,7}$ These outcomes usually occur as DS have a strong correlation with C-reactive protein (CRP) and inflammatory markers such as IL-6 and IL-8. ${ }^{6,7}$ Preoperative DS also affect long-term results up to five years following surgery, including the occurrence of new myocardial infarctions or angina, and reduced quality of life. $^{8,24}$

Likewise, postoperative DS have undesirable implications after CABG. Frequently, patients with increased postoperative DS complain of decreased quality of life and reduced compliance with medication regimens. ${ }^{4,6}$ Also, postoperative DS increase hospital readmissions and LOS, while reducing the ability to walk and wound healing. ${ }^{4,5,19,25}$

Conversely, shorter LOS is associated with increased speed of recovery, including surgical, physical, and longterm recovery. ${ }^{7,8,20}$ Recently, health care administrators have executed policies to discharge postoperative CABG patients within 5 to 7 days, to decrease the load on the systems. ${ }^{7,8,20}$ For example, one day in the Intensive Care Unit (ICU) for postoperative CABG patients might cost nearly $1500 \$ .^{7,8,20}$ For this reason, researchers started to focus on studying DS and their relation to LOS among CABG patients.

Previous studies showed that DS increased LOS among post-CABG patients. Patients undergoing $\mathrm{CABG}$ are expected to stay longer in hospital if they develop complications and have poor retrieval. ${ }^{20}$ Every unit increase in preoperative DS has been found to increase LOS by 0.4 days (with an average LOS of 11.40 days in Jordan). ${ }^{20}$ Patients with high preoperative DS scores were three times more susceptible to stay in hospital more than seven days, which was mediated by high levels of CRP. ${ }^{7}$ This was reaffirmed by a subsequent study that controlled for all confounding variables, finding that DS were associated with socioeconomic status, with patients with low DS and high socioeconomic status having the shortest LOS. ${ }^{8}$ Conversely, those with high DS and low socioeconomic status had the highest LOS. Among 143 Jordanian participants (76 male and 67 female) who did CABG, it was found that greater DS were described by participants who had longer LOS in ICU. ${ }^{6}$

Considering the association between DS, specifically preoperative DS, and longer LOS, it is imperative to look for factors that decrease/control/mediate the consequence of preoperative DS on the LOS after CABG. Plenty of factors can affect DS, including but not limited to: age, gender, marital status, comorbidities, social support, monthly income, use of certain medications (eg, statins), and perceived control (PC) levels. ${ }^{6,20,23}$

Different studies showed that females have higher levels of DS across cultures and among different populations with heart problems, including heart failure and postCABG. ${ }^{6,13,20,26-31}$ However, other studies did not find this relationship, especially post-CABG, ${ }^{21,32,33}$ therefore this relationship still needs further clarification. ${ }^{15,34}$ Previous studies on the association between gender and LOS post-CABG are very limited. AbuRuz (2019) concluded that female 
patients experienced higher DS and therefore, stayed longer in the hospital since DS were autonomous predictor for increasing LOS. ${ }^{20}$ Moreover, in another study checking the moderating effect of PC on anxiety and LOS among postCABG patients, AbuRuz et al showed that women had greater levels of anxiety and had longer LOS in the hospital compared men, which was moderated by high levels of PC. ${ }^{35}$

$\mathrm{PC}$ is defined as "an individual's belief that he or she has the resources required to cope with negative events in a way that positively influences their adversive nature". ${ }^{35}$ To our knowledge, there are no studies checking the effect of $\mathrm{PC}$ on the DS and LOS among post-CABG patients. However, studies checking the effect of PC on anxiety among cardiac populations, including $\mathrm{CABG}$, were found in the literature. ${ }^{35}$ $\mathrm{PC}$ was found to be an independent predictor that decreases the LOS after CABG. When PC increased by one unit, postoperative LOS decreased by 5 hours. Moreover, PC moderated the effect of anxiety on LOS among CABG patients. This was indicated by the interaction between PC and anxiety levels on the LOS. When anxiety was high and PC was low, patients had the longest LOS. On the other hand, when anxiety was low and PC was high, the patients had the shortest LOS. ${ }^{35}$ Among other cardiac populations, higher levels of PC were associated with lower levels of anxiety in AMI, cardiac surgery, and heart failure, ${ }^{36-38}$ and better quality of life among cardiac transplant recipients. ${ }^{38}$

Consequently, the main goal of this study is to check if PC moderates the relationship between DS and LOS among patients undergoing CABG. Specifically, this study tests the following research hypotheses: H1: Preoperative DS levels will be high $(\geq 8)$. H2: Female patients will have higher DS levels and longer postoperative LOS compared to male patients. H3: DS scores and PC will predict postoperative LOS, after controlling for sociodemographic and clinical variables. H4: PC will moderate the effect of DS on LOS.

\section{Patients and Methods Design, Sample, and Setting}

This was a prospective cohort study among a consecutive sample of all patients who met the following eligibility criteria: (1) adult patients older than 18 years, (2) not an emergency operation, (3) free from depression diagnosis (as confirmed by a psychiatrist), (4) not on anti-depressant medications, (5) able to read and write in Arabic. Those patients were recruited from three hospitals in Amman, Jordan, comprising one governmental, one teaching, and one private hospital.

To make sure that the sample size was sufficient to run the appropriate statistical tests, power analysis was used to determine the sample size. This study thus used one sample $t$-test for hypothesis one, independent sample $t$-test for hypothesis 2 , and multiple regression for hypotheses 3 and 4, with 12 independent variables, subject to the following assumptions alpha coefficient of 0.05 , power of 0.95 , and a medium effect size between DS and LOS. Based on that, the needed sample size was 54 patients for hypothesis one, 210 patients for hypothesis 2, and 184 patients for hypotheses 3 and 4 . Recruitment continued until the sample reached 220 patients (Figure 1).

\section{Procedure}

Study purpose, benefits and risks were explained to all participants at the cardiology clinics of the selected hospitals by well-trained cardiovascular research assistants. Participants were informed that their participation was voluntary and that they could withdraw from the study at any time without affecting their usual care. Participants

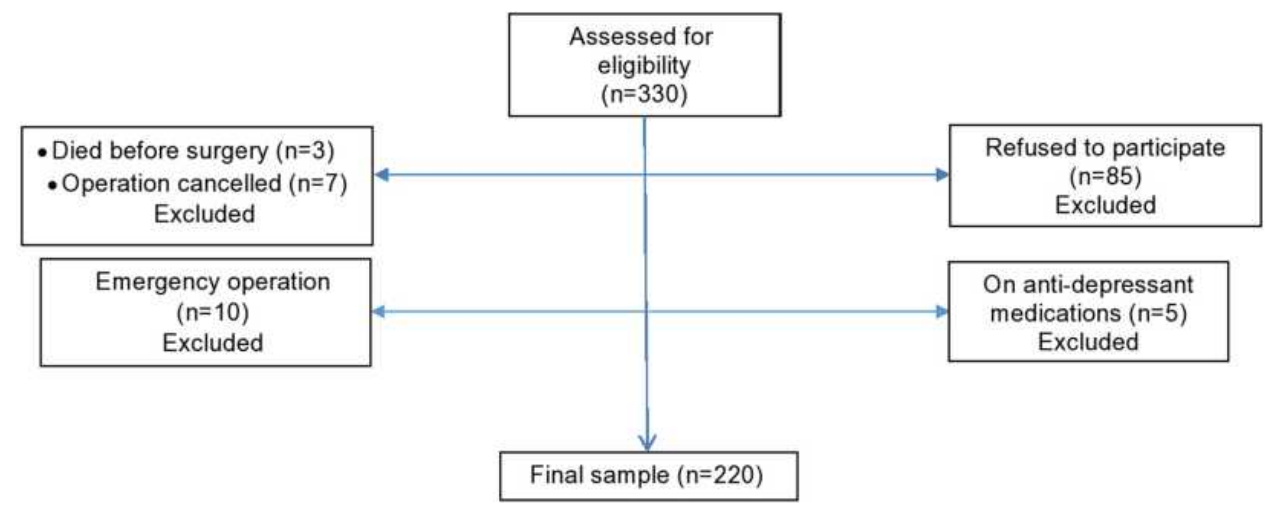

Figure I Patients flow diagram. 
signed an informed consent form if they agreed to participate. A research assistant assessed participants' DS level by administering the depression subscale of the Hospital Anxiety and Depression Scale (HADS) within two days before surgery. Also, participants completed a sociodemographic sheet about age, gender, marital status, and monthly income. Other clinical data including postoperative hospital LOS, history of comorbidities (ie, diabetes mellitus (DM), hypertension (HTN), previous angina, and previous myocardial infarction) and body mass index (BMI, in $\mathrm{kg} / \mathrm{m}^{2}$ ) were collected from medical records after discharge.

\section{Measurement of Variables}

DS: measured by the Arabic depression subscale of the HADS. This subscale has seven Likert-type items ranging from 0 to 3 for each item. The total scores can range from 0 to 21 , with higher scores indicating higher symptoms frequency and severity. Scores were classified as follows: (0-7) normal, and 8-21 high. ${ }^{39,40}$ The Cronbach's $\alpha$ for the Arabic depression subscales was $0.87 .^{40-44}$

PC: was measured by the Arabic version of the Control Attitude Scale-Revised (CAS-R). This instrument has been used in previous studies among cardiac populations, and showed acceptable psychometric properties, with a Cronbach's $\alpha$ for the Arabic version of $0.75 .{ }^{16,35}$ This instrument comprises eight Likert-type items, each of which has five option answers, ranging from 1 "totally disagree" to 5 "totally agree". The total range is from 8 to 40 , with higher scores reflecting greater levels of PC. ${ }^{16,35}$ Since there are no published mean norms, the median was used to classify participants with high and low PC. ${ }^{16,35}$

LOS: After discharge, LOS was recorded in days, and was obtained from medical archives.

\section{Ethical Considerations}

This study was formally approved by the IRB committee at the Applied Science Private University, Amman, Jordan, and by the selected hospitals. Informed consent was signed by all eligible participants who agreed to participate. All informations were dealt with complete confidentiality and reserved in a protected cupboard at the principal investigator's office.

\section{Data Analysis}

SPSS version 24 was used for the analysis. H1 (Preoperative DS will be high $(\geq 8)$ ) was tested by one group difference from a constant; H2 (Female patients will have higher DS and longer postoperative LOS compared to male patients) was tested by independent sample $t$-test. H3 (DS and PC will predict postoperative LOS, after controlling for sociodemographic and clinical variables) and H4 (PC will moderate the effect of DS on LOS) were tested by stepwise multiple regression, followed by simple slope analysis of \pm 1 SD from the mean.

In the first model, PC scores, DS scores, and all sociodemographic and clinical variables were entered. In the second model, the interaction between centralized PC and DS was included.

An additional check for $\mathrm{H} 4$ involved creating four categories of participants based on DS (low $\leq 7$ and high $\geq 8$ ), with a median PC split of 29. These four categories were: low DS/high PC, low DS/low PC, high DS/high PC, and high DS/low PC. The LOS among the four groups was then compared using ANOVA, with post hoc analysis.

\section{Results}

\section{Participant Characteristics}

Two hundred and twenty patients (160 men and 60 women) were included in this study. More than half of the sample was married, and a minority was working. Eighty percent were hypertensive, and more than $90 \%$ had previous angina. Two-thirds of the sample had high DS levels in the preoperative period. Other characteristics are presented in Table 1.

\section{Hypotheses Testing}

H1 (Preoperative DS levels will be high $(\geq 8)$ ) was tested by one group difference from a constant, which showed that preoperative DS levels were significantly higher than 8 (mean [SD]: 12.80 [5.8], $\mathrm{P}<0.001$ ).

$\mathrm{H} 2$ (Female patients will have higher DS levels and longer postoperative LOS compared to male patients) was tested by independent sample $t$-test, one for DS and one for LOS. These tests showed that females had higher levels of DS (mean [SD]: 16.7 [5.2] vs.11.6 [5.6], $\mathrm{P}<0.05$ ), and longer LOS (mean [SD]: 17.5 [12.7] vs.10.3 [9.0], $\mathrm{P}<0.001$ ) compared to male patients.

H3 (DS scores and PC will predict postoperative LOS, after controlling for sociodemographic and clinical variables) and H4 (PC will moderate the effect of DS on LOS) were tested using multiple regression followed by simple slope analysis. The results of the regression analysis are presented in Table 2. Being female increased LOS by 0.18 
Table I Clinical and Sociodemographic Characteristics ( $N=220)$

\begin{tabular}{|c|c|}
\hline Characteristics & Mean \pm SD or $n(\%)$ \\
\hline Age & $69.5 \pm 9.4$ \\
\hline \multicolumn{2}{|l|}{ Gender } \\
\hline Male & $160(72.7)$ \\
\hline Female & $60(27.3)$ \\
\hline \multicolumn{2}{|l|}{ Marital status } \\
\hline Married & $134(60.9)$ \\
\hline Single/divorced/widowed & $86(39.1)$ \\
\hline \multicolumn{2}{|l|}{ Income/month } \\
\hline$<1000 \$$ & $140(63.7)$ \\
\hline$\geq 1001 \$$ & $80(36.3)$ \\
\hline Currently working & $31(14.1)$ \\
\hline History of HTN & $176(80.0)$ \\
\hline History of DM & $125(56.8)$ \\
\hline History of previous AMI & $143(65.0)$ \\
\hline History of previous angina & $199(90.5)$ \\
\hline \multicolumn{2}{|l|}{ Smoking History } \\
\hline Never smoked & $61(27.7)$ \\
\hline Current smoker & $66(30.0)$ \\
\hline Former smoker & $93(42.3)$ \\
\hline Post-operative hospital LOS & $10.9 \pm 10.4$ \\
\hline BMI $\left(\mathrm{kg} / \mathrm{m}^{2}\right)$ & $26.8 \pm 4.6$ \\
\hline Total CAS-R & $20.0 \pm 5.3$ \\
\hline Pre-operative depressive symptoms & $12.8 \pm 6.8$ \\
\hline Normal & $99(45.0)$ \\
\hline High & $|2|(55.0)$ \\
\hline
\end{tabular}

Abbreviations: AMI, acute myocardial infarction; BMI, body mass index; CAS-R, control attitude scale revised; DM, diabetes mellitus; HTN, hypertension.

days. Every one unit increase in preoperative DS level increased LOS by 0.37 days. PC has a protective effect; every one unit increase in PC decreased LOS by 0.28 days. The interaction term in Model 2 was significant. Furthermore, the $\mathrm{R}^{2}$ change between Model 1 and Model 2 was significant $\left(\Delta \mathrm{R}^{2}=0.09, \mathrm{P}<0.01\right)$. These results indicated that $\mathrm{PC}$ was a significant moderator in the relationship between preoperative DS and LOS.

In simple slope analysis; which simply means, checking the impact of an independent variable (preoperative DS levels) on the dependent variable (LOS) when the moderator (PC) is high (1 SD) above and low (1 SD) below the mean. This test showed that preoperative DS increased the LOS when the moderator $(\mathrm{PC})$ was low (simple slope $=0.43, t=7.1$,
Table 2 Predictors of Postoperative Hospital LOS by Stepwise Regression Analysis ( $\mathrm{N}=220)$

\begin{tabular}{|l|c|c|c|c|}
\hline \multirow{2}{*}{ Variable } & \multicolumn{2}{|c|}{ Model I } & \multicolumn{2}{c|}{ Model 2 } \\
\cline { 2 - 5 } & $\begin{array}{c}\text { Standardized } \\
\boldsymbol{\beta}\end{array}$ & $\mathbf{t}$ & $\begin{array}{c}\text { Standardized } \\
\boldsymbol{\beta}\end{array}$ & $\mathbf{t}$ \\
\hline Female gender & $0.19^{*}$ & 2.9 & $0.18^{* *}$ & 2.8 \\
\hline $\begin{array}{l}\text { Pre-op } \\
\text { depression }\end{array}$ & $0.33^{* *}$ & 5.6 & $0.37^{* *}$ & 6.8 \\
\hline PC scores & $-0.29 * *$ & -5.1 & $-0.28^{* *}$ & -4.71 \\
\hline $\begin{array}{l}\text { Depression } \\
\text { scores } \times P C\end{array}$ & & & $0.39 * *$ & 6.8 \\
\hline Adjusted $\mathrm{R}^{2}$ & 0.31 & & \multicolumn{2}{|c|}{0.40} \\
\hline F & 9.0 & $12.6 \mathrm{I}$ \\
\hline
\end{tabular}

Notes: ${ }^{*}<<0.05 ;{ }^{*} p<0.01$. In the first step, gender, age, income, marital status, history of hypertension, DM, previous MI, previous angina, use of statins, BMI, PC scores, and preoperative depression scores were entered as independent variables. In the second step, the interaction between centralized PC and preoperative depression was included.

Abbreviations: BMI, body mass index; DM, diabetes mellitus; LOS, length of stay; MI, myocardial infarction; PC, perceived control.

$P<0.001$ ), and this turns to be insignificant when the moderator (PC) was high. These results indicated that PC worked as a moderator between preoperative DS and LOS.

Further clarification of this moderating effect was concluded when comparisons were made among the four groups of PC and preoperative DS levels (low preoperative DS/high PC, low preoperative DS/low PC, high preoperative DS/high PC, and high preoperative DS/low PC). The results are demonstrated in Figure 2.

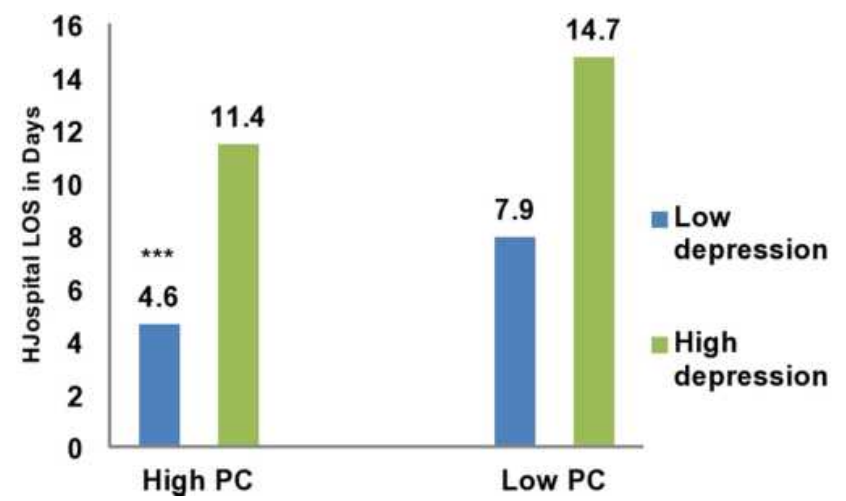

Figure 2 Comparison of LOS based on PC and preoperative depression level. Notes: Patients with low PC and high preoperative depression had the longest LOS, and those with high PC and low preoperative depression had the shortest LOS, indicating the moderating effect of PC on the relationship between preoperative depression and LOS. $* * * \mathrm{P}<0.001$.

Abbreviations: LOS, length of stay; PC, perceived control. 


\section{Discussion}

This study aimed to test if PC moderates the relationship between DS and LOS after CABG, exploring whether preoperative DS and PC predicted LOS after CABG. In addition, this study verified if female patients were more depressed compared to males, and if preoperative DS levels were high. The results showed that preoperative DS levels were high, females were more depressed than males, and both of them (preoperative DS and female gender) increased LOS. Furthermore, the results indicate that $\mathrm{PC}$ has a protective effect, which means that it decreases the LOS and moderates the relationship between DS and LOS.

In the current study, $55.0 \%$ of the patients had high levels of DS, within the range of previous studies (14-60\%). ${ }^{7,8,17-20}$ This wide range of prevalence might be due to one or more of the following causes: (1) different operational definitions of DS; (2) threshold levels for determining high or low levels of DS; (3) the time of measuring DS; (4) diverse inclusion and exclusion criterial; and (5) lack of control of confounding variables in previous studies (eg, the use of anti-depressants and statins).

The current study also displayed that preoperative DS levels were high and increased the LOS. These results are inline with previous researches. ${ }^{7,8,17,20}$ Preoperative DS levels were found to be high and to be an independent predictor that increased the LOS among 250 patients who underwent $\mathrm{CABG}^{20}{ }^{20} \mathrm{~A}$ meta-analysis of 39 prospective studies on depression and DS concluded that preoperative DS levels were connected with a drop of symptoms release and quicker reappearance of these symptoms. ${ }^{5}$ Furthermore, it is related with advanced rates of postoperative re-admissions and death. ${ }^{5,45,46}$

Discovering mechanisms connecting DS to underprivileged consequences proposes either one of three paths: organic, social, or interactive. Organically, DS work on hypothalamic pituitary adrenal access, tempering resistant roles and distressing immune cells that dysregulate the secretion of pro-inflammatory cytokines. ${ }^{7,18,20}$ Furthermore, the association between DS and LOS has been mediated by CRP, indicating a connection between DS and inflammation..$^{7,8,35,47}$ This inflammation is accountable for the undesirable outcomes after surgery. Socially and interactively, patients with low socioeconomic status and those with sleep deficiencies have worse postoperative outcomes. ${ }^{6,8,48}$ Furthermore, patients with high levels of
DS revealed opposing behavioral changes such as poor hygiene, changed nutritional status, and lack of medication compliance, all of which aggravate deleterious outcomes. ${ }^{8,18}$

Women had higher DS rates compared to men in this study. Previous studies among different cardiac populations demonstrated that women had higher DS levels compared to men. ${ }^{13,26-31}$ In Jordan, the same country where this study was conducted, two previous studies on the same population (post-CABG) showed that women were more depressed compared to men. ${ }^{6,20}$ Given that women had higher DS levels than men, and higher DS levels increase LOS, it is unsurprising that women had longer LOS in this study compared to men. However, some studies did not show this result. Explanations might be due to under-representation of women among these studies, or cases of differences in DS rates among these patients.

Previous studies ${ }^{20,27}$ also showed that females postCABG surgery have a more problematic recovery journey than men, which cannot be clarified by disease severity, pre-surgery conditions, or other client features. ${ }^{27}$ These results signify that an imperative role might be employed by the psychological conditions of patients on their results. ${ }^{27}$ In many cultures, especially Arabic ones like that of Jordan, women frequently play a bigger part in the home and household lifecycle (predominantly taking care of and teaching children). For these reasons, women might sense additional distraction in their lives, and thus feel more depressed when they cannot recommence their previous role in full after surgery. ${ }^{20,27}$

The last and the most important result in this study is that PC has a protective impact against LOS, and a moderating effect on the relationship between DS and LOS. It has been shown previously that PC had a dynamic part in the adaptation among different patients with cardiac disease. Psychological recovery from cardiac events depends mostly on psychological factors, rather than physical ones. A high level of PC is independently predictive of psychosocial recovery, and plays a more projecting role than physical predictors in defining psychosocial recovery. In a previous study about the effect of PC on anxiety and LOS after CABG, high levels of PC predicted shorter LOS and had a moderating effect on the relationship between anxiety and LOS. ${ }^{35}$ In other cardiac populations, higher levels of PC were associated with lower levels of anxiety and DS for the patients and their families. ${ }^{49-51} \mathrm{PC}$ has been found to moderate the undesirable influence of 
anxiety on in-hospital complications, such as recurrent ischemia, re-infarction, and malignant dysrhythmias after AMI. ${ }^{16,35}$

\section{Conclusions}

Preoperative DS among CABG patients are high, especially among women, and they are associated with increased LOS. Perceived control has a protective effect against this association, indicating its moderating action. Policies to assess DS prior to this type of surgery would greatly increase health care service efficiency for such patients, and the application of strategies to control these DS and decrease the burdens on cardiovascular disease care resources is warranted. Improving levels of perceived control among those patients might decrease the effect of postoperative DS and LOS.

\section{Study Limitations}

The major limitation of this study was the use of chart review in order to collect some of the data, as we depended on others for such information. Moreover, DS and perceived control levels were measured by selfreported questionnaires. Despite the used instruments being of demonstrable validity and reliability, having been widely used in clinical research, it is recommended that clinical evaluation of these variables among patients be undertaken with the assistance of a psychiatrist for more in-depth analysis, in addition to the instruments, to avoid any confounding factors or misdiagnoses. Another limitation is the relatively low number of female participants.

\section{Acknowledgment}

The authors are grateful to the Applied Science Private University, Amman, Jordan, for their help in conducting this research project.

\section{Disclosure}

The authors report no conflicts of interest in this work.

\section{References}

1. Virani SS, Alonso A, Aparicio HJ, et al. Heart disease and stroke statistics-2021 update: a report from the American Heart Association. Circulation. 2021;2021:CIR0000000000000950.

2. Mensah GA, Roth GA, Fuster V. The global burden of cardiovascular diseases and risk factors: 2020 and beyond. $\mathrm{J}$ Am Coll Cardiol. 2019;74(20):2529-2532. doi:10.1016/j.jacc.2019.10.009

3. Benjamin EJ, Virani SS, Callaway CW, et al. Heart disease and stroke statistics-2018 update: a report from the American Heart Association. Circulation. 2018;137(12):e67-e492.
4. Kidd T, Poole L, Leigh E, Ronaldson A, Jahangiri M, Steptoe A. Health-related personal control predicts depression symptoms and quality of life but not health behaviour following coronary artery bypass graft surgery. $J$ Behav Med. 2016;39(1):120-127. doi:10.1007/s10865-015-9677-7

5. Ravven S, Bader C, Azar A, Rudolph JL. Depressive symptoms after CABG surgery: a meta-analysis. Harv Rev Psychiatry. 2013;21 (2):59-69. doi:10.1097/HRP.0b013e31828a3612

6. Issa Hweidi BG, Al-Obeisat S, Al-Smadi A. Prevalence of depression and its associated factors in patients post-coronary artery bypass graft surgery. $J$ Res Nurs. 2018;23(1):76-88. doi:10.1177/ 1744987117728314

7. Poole L, Kidd T, Leigh E, Ronaldson A, Jahangiri M, Steptoe A. Depression, C-reactive protein and length of post-operative hospital stay in coronary artery bypass graft surgery patients. Brain Behav Immun. 2014;37:115-121. doi:10.1016/j.bbi.2013.11.008

8. Poole L, Leigh E, Kidd T, Ronaldson A, Jahangiri M, Steptoe A. The combined association of depression and socioeconomic status with length of post-operative hospital stay following coronary artery bypass graft surgery: data from a prospective cohort study. J Psychosom Res. 2014;76(1):34-40. doi:10.1016/j. jpsychores.2013.10.019

9. Yilmaz M, Sezer H, Gürler H, Bekar M. Predictors of preoperative anxiety in surgical inpatients. J Clin Nurs. 2012;21(7-8):956-964. doi:10.1111/j.1365-2702.2011.03799.x

10. Tully P, Pennett J, Baker R. Depression, anxiety, and cardiac morbidity outcomes after coronary artery bypass surgery: a contemporary and practical review. Geriatr Cardiol. 2011;40(1):4-11.

11. Mallik S, Krumholz HM, Lin ZQ, et al. Patients with depressive symptoms have lower health status benefits after coronary artery bypass surgery. Circulation. 2005;111(3):271-277. doi:10.1161/01. CIR.0000152102.29293.D7

12. Abramov D, Tamariz MG, Fremes SE, et al. Trends in coronary artery bypass surgery results: a recent, 9-year study. Ann Thorac Surg. 2000;70(1):84-90. doi:10.1016/S0003-4975(00)01249-2

13. AbuRuz ME, Alaloul F, Al-Dweik G. Depressive symptoms are associated with in-hospital complications following acute myocardial infarction. Appl Nurs Res. 2018;39:65-70. doi:10.1016/j. apnr.2017.11.001

14. Huffman JC, Smith FA, Blais MA, Januzzi JL, Fricchione GL. Anxiety, independent of depressive symptoms, is associated with in-hospital cardiac complications after acute myocardial infarction. J Psychosom Res. 2008;65(6):557-563. doi:10.1016/j. jpsychores.2008.08.001

15. AbuRuz ME, Masa'Deh R. Gender differences in anxiety and complications early after acute myocardial infarction. J Cardiovasc Nurs. 2017;32(6):538-543. doi:10.1097/JCN.0000000000000375

16. AbuRuz ME. Perceived control moderates the relationship between anxiety and in-hospital complications after ST segment elevation myocardial infarction. J Multidiscip Healthc. 2018;11:359-365. doi:10.2147/JMDH.S170326

17. Oxlad M, Stubberfield J, Stuklis R, Edwards J, Wade TD. Psychological risk factors for increased post-operative length of hospital stay following coronary artery bypass graft surgery. J Behav Med. 2006;29(2):179-190. doi:10.1007/s10865-005-9043-2

18. Doering LV, Moser DK, Lemankiewicz W, Luper C, Khan S. Depression, healing, and recovery from coronary artery bypass surgery. Am J Crit Care. 2005;14(4):316-324. doi:10.4037/ ajcc2005.14.4.316

19. Tully PJ, Baker RA, Turnbull D, Winefield H. The role of depression and anxiety symptoms in hospital readmissions after cardiac surgery. J Behav Med. 2008;31(4):281-290. doi:10.1007/s10865-008-9153-8

20. AbuRuz ME. Pre-operative depression predicted longer hospital length of stay among patients undergoing coronary artery bypass graft surgery. Risk Manag Healthc Policy. 2019;12:75-83. doi:10.2147/RMHP.S190511 
21. Amouzeshi A, Hosseini SM, Javadi A, et al. Depression and associated factors in patients undergoing coronary artery bypass grafting in Imam Reza Hospital of Mashhad in 2013. J Surg Trauma. 2016;3 (3-4):51-56.

22. Freedland KE, Skala JA, Carney RM, et al. Treatment of depression after coronary artery bypass surgery: a randomized controlled trial. Arch Gen Psychiatry. 2009;66(4):387-396. doi:10.1001/ archgenpsychiatry.2009.7

23. Chaudhury S, Saini R, Bakhla AK, Singh J. Depression and anxiety following coronary artery bypass graft: current Indian scenario. Cardiol Res Pract. 2016;2016:2345184. doi:10.1155/2016/2345184

24. Burg MM, Benedetto MC, Rosenberg R, Soufer R. Presurgical depression predicts medical morbidity 6 months after coronary artery bypass graft surgery. Psychosom Med. 2003;65(1):111-118. doi:10.1097/01.PSY.0000038940.33335.09

25. Tully PJ, Baker RA, Knight JL. Anxiety and depression as risk factors for mortality after coronary artery bypass surgery. J Psychosom Res. 2008;64(3):285-290. doi:10.1016/j.jpsychores.20 07.09.007

26. Moser DK, Dracup K, Evangelista LS, et al. Comparison of prevalence of symptoms of depression, anxiety, and hostility in elderly patients with heart failure, myocardial infarction, and a coronary artery bypass graft. Heart Lung. 2010;39(5):378-385. doi:10.1016/j. hrtlng.2009.10.017

27. Vaccarino V, Lin ZQ, Kasl SV, et al. Gender differences in recovery after coronary artery bypass surgery. $\mathrm{J} \mathrm{Am}$ Coll Cardiol. 2003;41 (2):307-314. doi:10.1016/S0735-1097(02)02698-0

28. Nemati MH, Astaneh B. The impact of coronary artery bypass graft surgery on depression and anxiety. J Cardiovasc Med. 2011;12 (6):401-404. doi:10.2459/JCM.0b013e32834358e9

29. Mitchell RH, Robertson E, Harvey PJ, et al. Sex differences in depression after coronary artery bypass graft surgery. Am Heart J. 2005;150(5):1017-1025. doi:10.1016/j.ahj.2005.05.005

30. McCrone S, Lenz E, Tarzian A, Perkins S. Anxiety and depression: incidence and patterns in patients after coronary artery bypass graft surgery. Appl Nurs Res. 2001;14(3):155-164. doi:10.1053/ apnr.2001.24414

31. Duits AA, Duivenvoorden HJ, Boeke S, et al. The course of anxiety and depression in patients undergoing coronary artery bypass graft surgery. J Psychosom Res. 1998;45(2):127-138. doi:10.1016/S00223999(97)00307-3

32. Shafiei Z, Babaee S, Nazari A. The effectiveness of massage therapy on depression, anxiety and stress of patients after coronary artery bypass graft surgery. Iran J Pediatr. 2013;21(1).

33. Sharif F, Shoul A, Janati M, Kojuri J, Zare N. The effect of cardiac rehabilitation on anxiety and depression in patients undergoing cardiac bypass graft surgery in Iran. BMC Cardiovasc Disord. 2012;12 (1):40. doi:10.1186/1471-2261-12-40

34. Serpytis P, Navickas P, Lukaviciute L, et al. Gender-based differences in anxiety and depression following acute myocardial infarction. Arq Bras Cardiol. 2018;111(5):676-683. doi:10.5935/ abc. 20180161

35. AbuRuz ME, Al-Dweik G, Al-Akash HY. Checking the moderating effect of perceived control on the relationship between anxiety and postoperative hospital length of stay among coronary artery bypass graft patients. Int $J$ Gen Med. 2019;12:79-85. doi:10.2147/IJGM. S192333

36. Ballash N, Pemble M, Usui W, Buckley A, Woodruff-Borden J. Family functioning, perceived control, and anxiety: a mediational model. J Anxiety Disord. 2006;20(4):486-497. doi:10.1016/j. janxdis.2005.05.002
37. Donovan H, Hartenbach E, Method M. Patient-provider communication and perceived control for women experiencing multiple symptoms associated with ovarian cancer. Gynecol Oncol. 2005;99 (2):404-411. doi:10.1016/j.ygyno.2005.06.062

38. Evangelista L, Moser D, Dracup K, Doering L, Kobashigawa J. Functional status and perceived control influence quality of life in female heart transplant recipients. J Heart Lung Transplant. 2004;23 (3):360-367. doi:10.1016/S1053-2498(03)00196-7

39. AbuRuz ME. Anxiety and depression predicted quality of life among patients with heart failure. J Multidiscip Healthc. 2018;11:367-373. doi:10.2147/JMDH.S170327

40. Bjelland I, Dahl AA, Haug TT, Neckelmann D. The validity of the hospital anxiety and depression scale. An updated literature review. J Psychosom Res. 2002;52(2):69-77. doi:10.1016/S0022-3999(01) 00296-3

41. Al Aseri ZA, Suriya MO, Hassan HA, et al. Reliability and validity of the hospital anxiety and depression scale in an emergency department in Saudi Arabia: a cross-sectional observational study. BMC Emerg Med. 2015;15:28. doi:10.1186/s12873-015-0051-4

42. el-Rufaie OE, Absood GH. Retesting the validity of the Arabic version of the Hospital Anxiety and Depression (HAD) scale in primary health care. Soc Psychiatry Psychiatr Epidemiol. 1995;30 (1):26-31. doi:10.1007/BF00784431

43. el-Rufaie OE, Albar AA, Al-Dabal BK. Identifying anxiety and depressive disorders among primary care patients: a pilot study. Acta Psychiatr Scand. 1988;77(3):280-282. doi:10.1111/j.16000447.1988.tb05121.x

44. el-Rufaie OE, Absood G. Validity study of the hospital anxiety and depression scale among a group of Saudi patients. Br J Psychiatry. 1987;151:687-688. doi:10.1192/bjp.151.5.687

45. Gallagher R, McKinley S. Anxiety, depression and perceived control in patients having coronary artery bypass grafts. J Adv Nurs. 2009;65 (11):2386-2396. doi:10.1111/j.1365-2648.2009.05101.x

46. McKhann GM, Borowicz LM, Goldsborough MA, Enger C, Selnes OA. Depression and cognitive decline after coronary artery bypass grafting. Lancet. 1997;349(9061):1282-1284. doi:10.1016/ S0140-6736(96)09466-4

47. Kiecolt-Glaser JK, Glaser R. Depression and immune function: central pathways to morbidity and mortality. J Psychosom Res. 2002;53 (4):873-876. doi:10.1016/S0022-3999(02)00309-4

48. Gallo LC, Matthews KA. Understanding the association between socioeconomic status and physical health: do negative emotions play a role? Psychol Bull. 2003;129(1):10-51. doi:10.1037/00332909.129.1.10

49. Moser D, Riegel B, McKinley S, Doering L, An K, Sheahan S. Impact of anxiety and perceived control on in-hospital complications after acute myocardial infarction. Psychosom Med. 2007;69 (1):10-16. doi:10.1097/01.psy.0000245868.43447.d8

50. Dracup K, Erickson V, Canary C, Moser D. Perceived control reduces emotional stress in patients with heart failure. J Heart Lung Transplant. 2003;22(1):90-93. doi:10.1016/S1053-2498(02)00454-0

51. Moser D, Dracup K. Impact of cardiopulmonary resuscitation training on perceived control in spouses of recovering cardiac patients. Res Nurs Health. 2000;23(4):270-278. doi:10.1002/1098-240X (200008)23:4<270::AID-NUR3>3.0.CO;2-8 


\section{Publish your work in this journal}

Risk Management and Healthcare Policy is an international, peerreviewed, open access journal focusing on all aspects of public health, policy, and preventative measures to promote good health and improve morbidity and mortality in the population. The journal welcomes submitted papers covering original research, basic science, clinical \& epidemiological studies, reviews and evaluations, guidelines, expert opinion and commentary, case reports and extended reports. The manuscript management system is completely online and includes a very quick and fair peer-review system, which is all easy to use. Visit http://www.dovepress.com/testimonials.php to read real quotes from published authors.

Submit your manuscript here: https://www.dovepress.com/risk-management-and-healthcare-policy-journal 